\title{
Nerve Growth Factor Promotes Survival of Septal Cholinergic Neurons After Fimbrial Transections
}

\author{
Franz Hefti \\ Department of Neurology, University of Miami School of Medicine, Miami, Florida 33101
}

Several findings obtained in recent years suggest that NGF, aside from its well-established function as a neurotrophic factor for peripheral sympathetic and sensory neurons, also has trophic influence on the cholinergic neurons of the basal forebrain. The present study assessed whether NGF was able to affect survival of central cholinergic neurons after axonal transections in adult rats. The septo-hippocampal pathway was transected unilaterally by cutting the fimbria, and animals were implanted with a cannula through which NGF or control solutions were injected intraventricularly over 4 weeks. The lesions reduced the number of large cell bodies, as visualized by Nissl staining in the medial septal nucleus and in the vertical limb of the diagonal band of Broca. Furthermore, in the same nuclei, they reduced the number of cell bodies positively stained for $\mathrm{AChE}$ after pretreatment with diisopropylfluorophosphate (a method known to result in reliable identification of cholinergic neurons in the septal area). On lesioned sides, the number of cholinergic cells in medial septal nucleus and the vertical limb of the diagonal band was reduced by $50 \pm 4 \%$, as compared to the number on contralateral sides. On lesioned sides of animals chronically treated with NGF, the number of AChE-positive cells in these areas was reduced only by $12 \pm 6 \%$, as compared to control levels. These findings suggest that fimbrial transections resulted in retrograde degeneration of cholinergic septo-hippocampal neurons and that NGF treatment strongly attenuated this lesion-induced degeneration. Rat septo-hippocampal cholinergic neurons belong to the group of ascending forebrain cholinergic neurons that is homologous to the population of cholinergic neurons that seems to selectively degenerate in Alzheimer's disease. The findings reported here, therefore, suggest that increasing the availability of NGF to cholinergic neurons might prevent or reduce their degeneration.

Nerve growth factor is normally believed to be a selective neurotrophic factor for sympathetic and sensory neurons of the peripheral nervous system (Greene and Shooter, 1980; Thoenen and Barde, 1980; Varon and Adler, 1980; Vinores and Guroff, 1980). However, several findings obtained in recent years suggest the possibility that the ascending cholinergic neurons of the basal rat forebrain respond to NGF. First, NGF, as well as the mRNA coding for NGF, are present in the rat brain and their levels seem to be highest in the hippocampus, i.e., in a target

\footnotetext{
Received July 15, 1985; revised Dec. 2, 1985; accepted Feb. 14, 1986.

The author was supported by the National Parkinson Foundation, Miami, FL, and the Alzheimer's Disease and Related Disorders Association, Chicago, IL. He is indebted to Dr. A. Dravid, Basel, Switzerland, for his contribution to the development of the lesion technique, and to Ms. A. Salvatierra for technical assistance.

Correspondence should be addressed to Dr. F. Hefti, Dept. of Neurology, University of Miami, P.O. Box 016960, Miami, FL 33101.

Copyright (C) 1986 Society for Neuroscience $0270-6474 / 86 / 082155-08 \$ 02.00 / 0$
}

area of forebrain cholinergic neurons (Crutcher and Collins, 1982; Korsching et al., 1985; Shelton and Reichardt, 1986). Second, NGF injected into target areas of forebrain cholinergic neurons (i.e., hippocampus and cortex) is taken up by nerve terminals and transported in a retrograde fashion to the cholinergic cell bodies located in the basal forebrain (Schwab et al., 1979; Seiler and Schwab, 1984). Since NGF uptake is mediated by specific receptors, these findings suggest the existence of NGF receptors on cholinergic neurons. The presence of NGF receptors on forebrain cholinergic neurons has recently been directly demonstrated using receptor autoradiography (Riopelle et al., 1985). Third, stimulation of NGF receptors on cholinergic neurons results in an elevation of the activity of CAT, the key enzyme in the synthesis of $\mathrm{ACh}$, in cultures containing cholinergic neurons of the fetal rat forebrain (Hefti et al., 1985; Honegger and Lenoir, 1982), in the brain of adult rats with partial lesions of a cholinergic pathway (Hefti et al., 1984), and in adult rats receiving transplants of fetal septal tissue (Toniolo et al., 1985). Fourth, the notion that NGF acts as a neurotrophic factor for forebrain cholinergic neurons is supported by results from lesion studies. Destruction of the cholinergic input to the hippocampus results in an ingrowth of peripheral sympathetic fibers that matches the previous distribution of cholinergic terminals in the hippocampus (Crutcher et al., 1979; Loy and Moore, 1977; Stenevi and Bjorklund, 1978). Since peripheral sympathetic neurons react to NGF, it has been postulated that the hippocampal signal attracting sympathetic fibers is identical to NGF, and that, in intact brains, NGF acts upon and is taken up by the cholinergic terminals in this area (Crutcher and Davis, 1981).

In the experiments on adult rats with partial transections of the fimbria, intraventricular applications of NGF over 4 weeks were found to increasc CAT activity in the hippocampus (Hefti et al., 1984). However, this effect was only transitory, since CAT activity in NGF-treated animals was found to be equal to that of control animals when measured several weeks after termination of the NGF applications (Will and Hefti, 1985). Furthermore, the NGF-mediated increase in hippocampal CAT activity was not accompanied by an increased density of cholinergic fibers in this area (Hefti et al., 1984). On the basis of these findings, it was concluded that NGF transitorily stimulates CAT synthesis in remaining cholinergic fibers without affecting their regenerative growth. However, in these experiments, NGF treatment, besides stimulating CAT activity in the hippocampus, resulted in increased CAT activity in septum, and this increase in septal CAT activity was not transitory, as it was still present several weeks after termination of the NGF applications (Hefti et al., 1984; Will and Hefti, 1985). On the basis of these findings, it was hypothesized that NGF might affect survival of septal cholinergic neurons. I now report that NGF is able to promote survival of forebrain cholinergic neurons after axonal injury in vivo. 


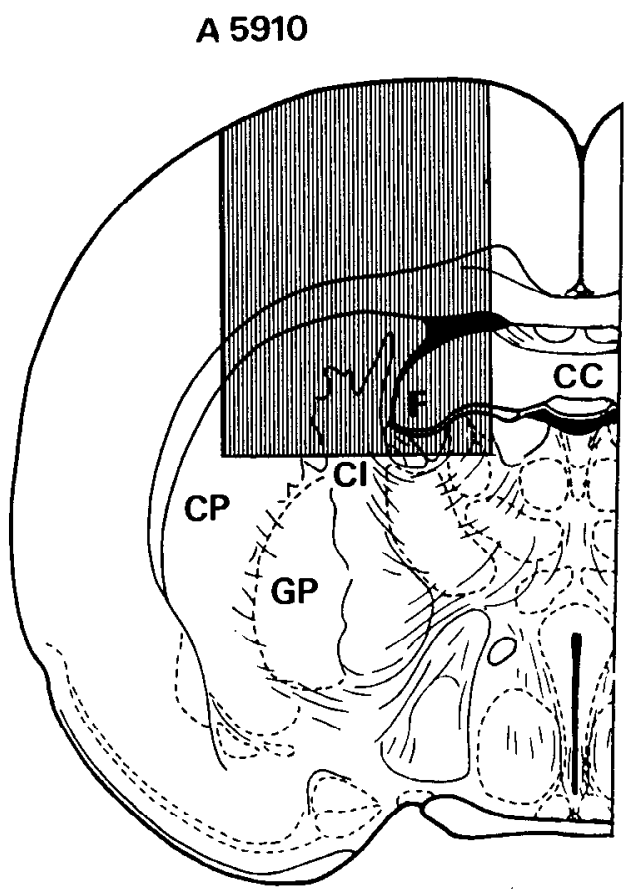

Figure 1. Transection of the fimbria as performed in the present study. At anteroposterior level A6100 (Koenig and Klippel, 1963), a specially designed knife was inserted into the brain and moved laterally. Because of the elasticity of the fimbria, and to ensure its transection, it was necessary to move the knife further laterally than the fimbria's normal lateral position. $C C$, Corpus callosum; $C I$, internal capsule; $C P$, caudate putamen; $F$, fornix; $G P$, globus pallidus.

\section{Materials and Methods}

\section{Fimbrial transections and NGF treatment}

The septo-hippocampal fibers were transected in adult female Wistar rats $(200 \mathrm{gm})$ by cutting the fimbria. A specially designed knife was lowered into the brain at anteroposterior level A6000 (according to the atlas of Koenig and Klippel, 1963) and at a position $1.0 \mathrm{~mm}$ lateral to the midline. The knife was moved vertically into the brain until its tip reached the dorsoventral level of $0.5 \mathrm{~mm}$. It was then moved laterally to $4.0 \mathrm{~mm}$ lateral to the midline and retrieved at this position (see Fig. 1). After making the lesion, a cannula was inserted into the lateral ventricle of the lesioned side and permanently fixed. Twice weekly, the lesioned animals received intraventricular injections of mouse $2.5 \mathrm{~S}$ NGF $(10 \mu \mathrm{g}$ in $5 \mu \mathrm{l}$ of saline) or of an equal amount of control protein (cytochrome $c$, which has biochemical properties similar to those of NGF, but no activity on NGF receptors; see Hefti et al., 1985).

\section{Histochemistry}

Four weeks after lesioning, NGF-treated and control animals were sacrificed and their brains were taken for histochemical analysis. Cholinergic cell bodies were visualized using AChE histochemistry after pretreatment with diisopropylfluorophosphate (DFP), following Butcher et al. (1975). Animals received $2 \mathrm{mg} / \mathrm{kg}$ of DFP and were killed $8 \mathrm{hr}$ later by intracordial perfusion with PBS containing 4\% formaldehyde, $1 \%$ glutaraldehyde, and $5 \%$ sucrose. Brains were frozen and frontal sections of $30 \mu \mathrm{m}$ thickness were cut and taken for Nissl staining using cresyl violet (Clark, 1981), or for visualization of AChE (Geneser-Jenden and Blackstad, 1979).

For AChE histochemistry, brain sections were incubated for $1 \mathrm{hr}$ at $37^{\circ} \mathrm{C}$ in $50 \mathrm{~mm}$ acetate buffer, $\mathrm{pH} 5.0$, containing $4 \mathrm{~mm}$ acetylthiocholine, $2 \mathrm{~mm}$ cupric sulfate, and $10 \mathrm{~mm}$ glycine. Nonspecific esterases were inhibited by inclusion of $0.2 \mathrm{~mm}$ of ethopropazine in the incubation medium. Sections were rinsed with $\mathrm{H}_{2} \mathrm{O}$, exposed for $1 \mathrm{~min}$ to $1.25 \%$ $\mathrm{Na}_{2} \mathrm{~S}$, washed with $\mathrm{H}_{2} \mathrm{O}$, and exposed for 1 min to $1 \% \mathrm{AgNO}_{3}$. The sections were then washed with $\mathrm{H}_{2} \mathrm{O}$, dehydrated, and mounted. Specificity of the staining was tested using the AChE inhibitor 1,5-bis(4allyldimethylammoniumphenyl)pentan-3-on dibromide (BW 284C51).

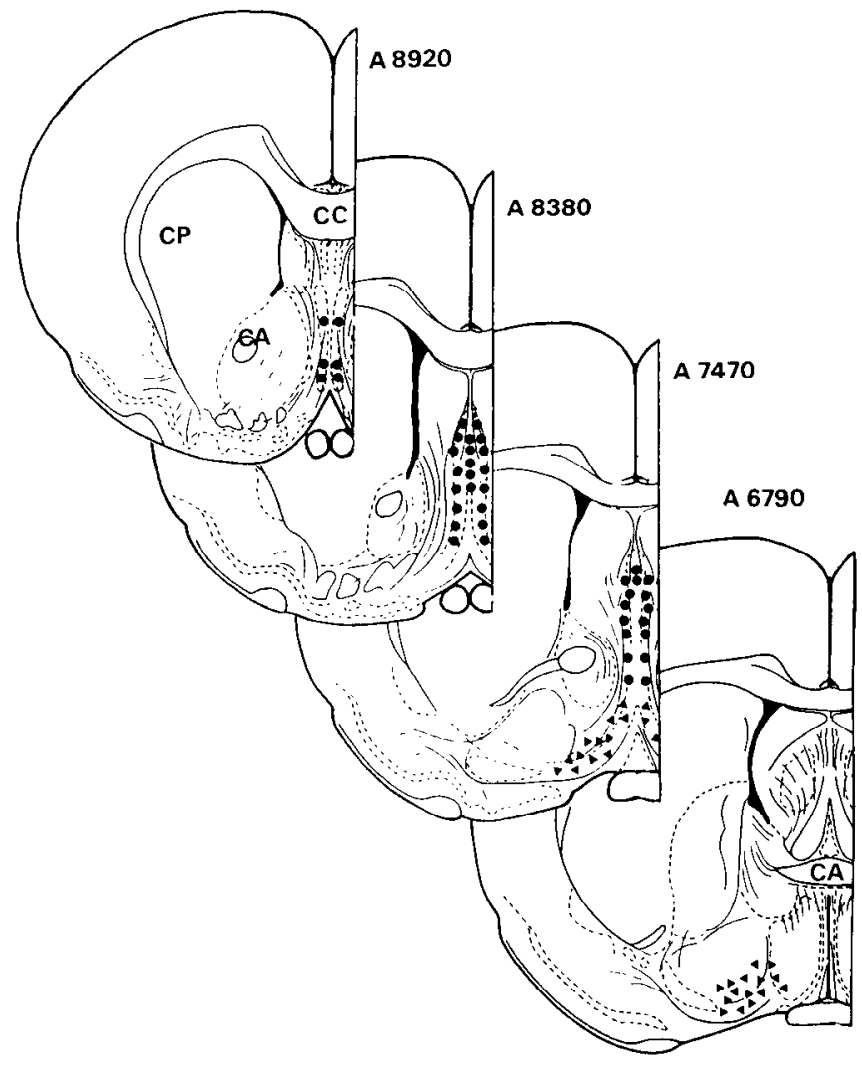

Figure 2. Counting of cholinergic neurons in animals with fimbrial transections. Brains were sectioned in a standardized manner, and neurons were counted between anteroposterior levels A6700 and A9000 (Koenig and Klippel, 1963). Cholinergic neurons were ascribed to one of the following two groups: first, to medial septal nucleus and the vertical limb of the diagonal band of Broca (i.e., areas containing cholinergic neurons projecting to hippocampus; dots); second, to the horizontal limb of the diagonal band of Broca and substantia innominata (i.e., areas containing cholinergic neurons not projecting to the hippocampus; triangles). $C A$, Anterior commissure; $C C$, corpus callosum; $C P$, caudate putamen.

\section{Cell counting}

To count cholinergic cell bodies in the septal area, brains of lesioned animals were cut in a standardized manner. The sectioned part of the brain contained the entire medial septal nucleus and the diagonal band of Broca, i.e., the areas containing cell bodies projecting to the hippocampus (McKinney et al., 1983; Fig. 2). Twenty-four sections $(30 \mu \mathrm{m})$ were taken between anteroposterior levels $A 6700$ and $A 9000$ (Koenig and Klippel, 1963), and the number of AChE-positive cell bodies was counted using a Leitz Dialux 22 microscope. The total number of cholinergic cell bodies was calculated by multiplying the number of counted cells in 24 sections by 3 , thereby accounting for the fact that only every third section was taken for analysis. Cells were assigned to medial septal nucleus, the vertical limb of the diagonal band of Broca, the horizontal limb of the diagonal band of Broca, and substantia innominata, as defined by McKinney et al. (1983). The border between the vertical and horizontal limb of the diagonal band was defined as shown in Figure 2.

\section{Materials}

Chemicals of analytical grade were obtained from Sigma or Mallinckrodt. Mouse NGF was purified from adult mouse submandibular glands according to the method of Bocchini and Angcletti (1969), with the modifications described by Suda et al. (1978).

\section{Resuits}

\section{Effects of lesion}

Unilateral fimbrial transections resulted in a loss of large cell bodies, visualized by Nissl staining, in the areas of the medial 

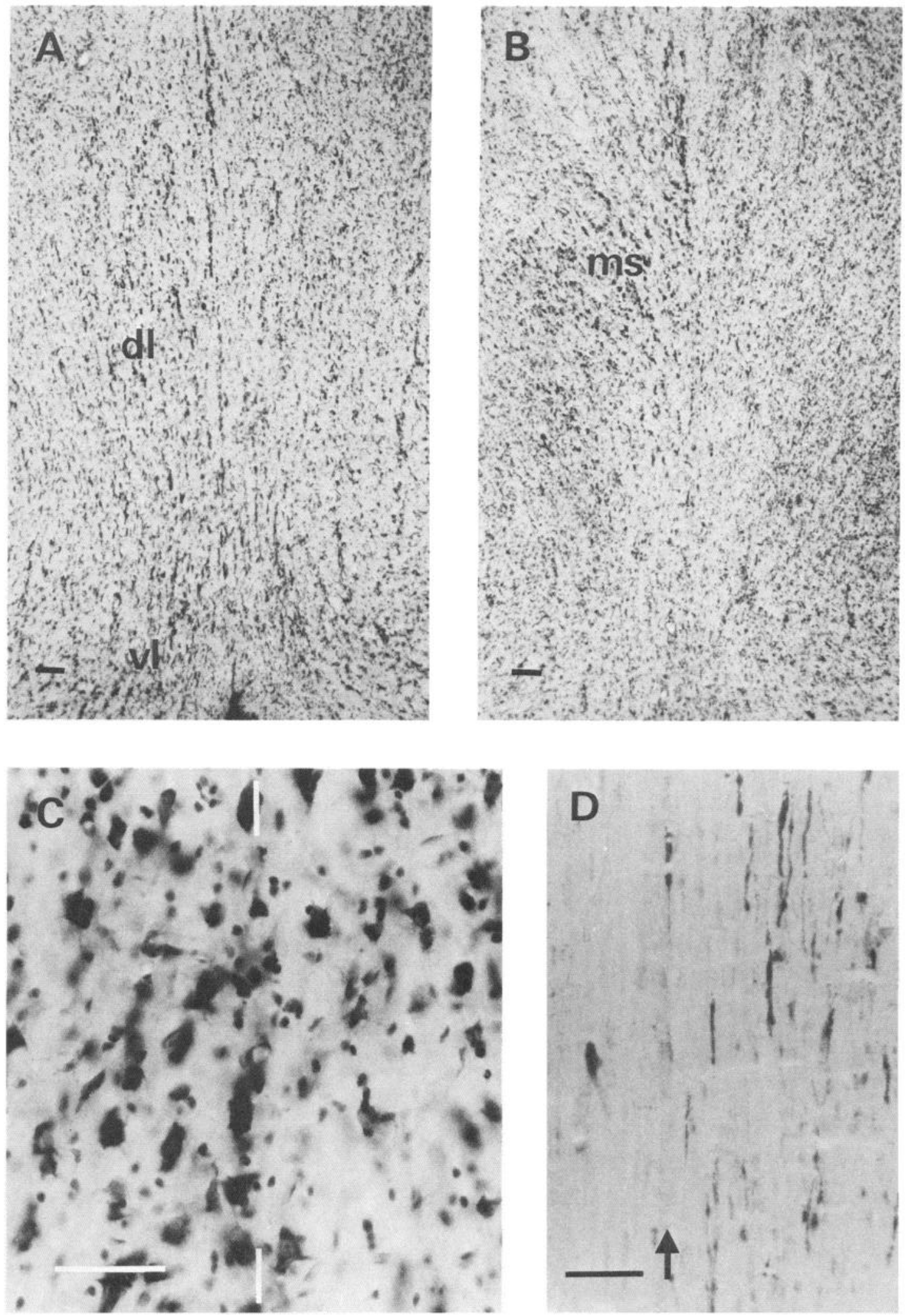

Figure 3. Neuronal degeneration after unilateral fimbrial transection. $A-C$, Sections taken for Nissl staining 3 weeks after lesioning. $A$ corresponds to level A8400; $B$ and $C$ to level 7000 of the atlas of Koenig and Klippel (1963; see Fig. 2). C, Vertical bars indicate the median of the brain. A reduction of the number of large cell bodies is evident on lesioned (right) sides. $D$, A section stained for AChE $4 \mathrm{~d}$ after lesioning. Arrow indicates the median of the brain. Swollen fibers, indicative of degenerative changes, are visible on the lesioned side. Bars, $100 \mu \mathrm{m}$ in $A, B$, and $D ; 50 \mu \mathrm{m}$ in $C . m s$, Medial septal nucleus; $v l$, horizontal (ventral) limb of the diagonal band of Broca; $d l$, dorsal (vertical) limb of the diagonal band of Broca. 

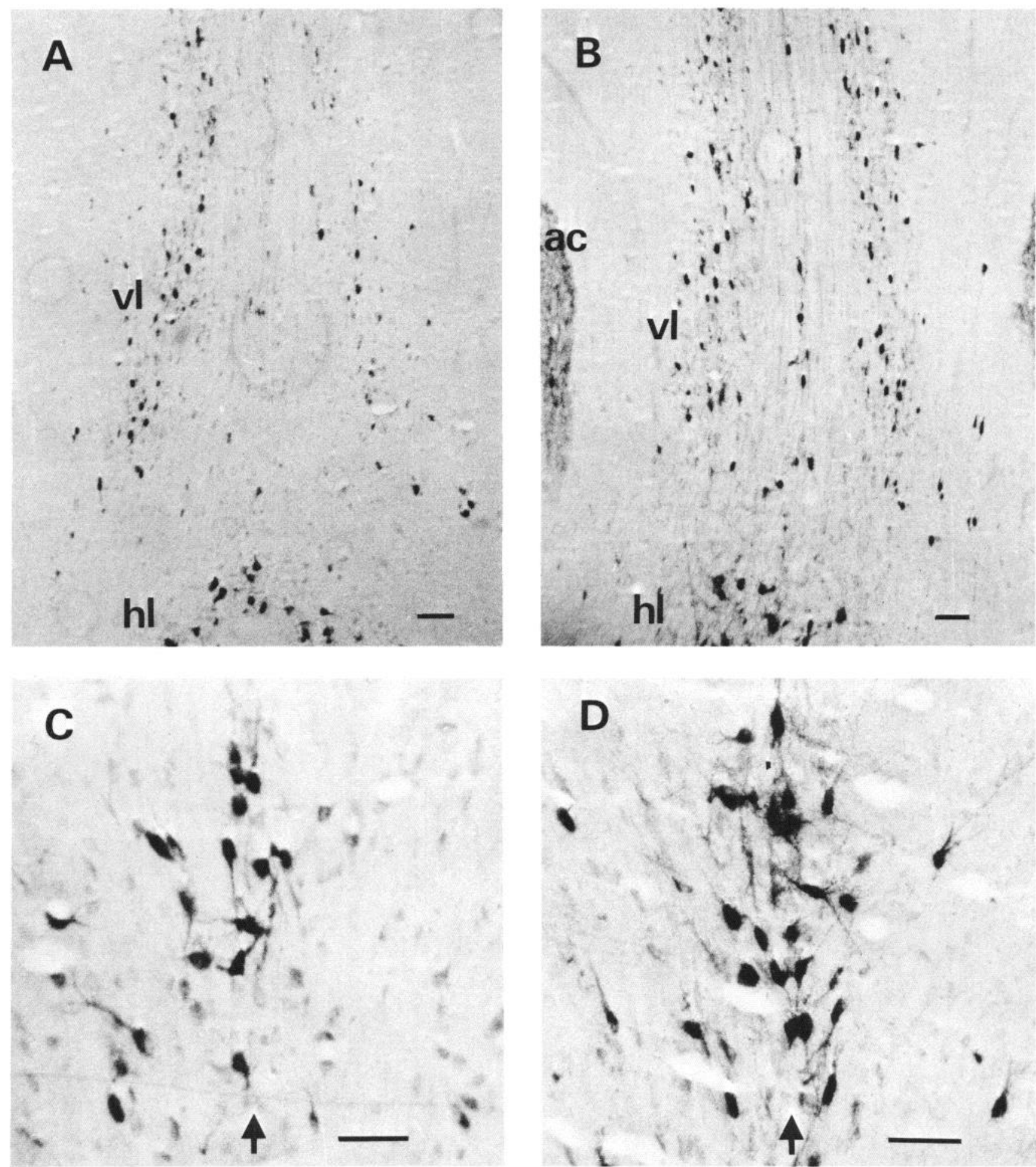

Figure 4. Effect of intraventricular administration of NGF on cholinergic neurons in medial septal nucleus after axonal transections. Rats received unilateral fimbrial transections and were then injected intraventricularly over 4 weeks with NGF (10 $\mu \mathrm{g}$ twice weekly) or with equal amounts of a control protein. Four weeks after lesioning, animals were taken for visualization of cholinergic cell bodies, using AChE histochemistry after pretreatment with DFP. $A$, Septal area of a lesioned control animal. $B$, Same area of a lesioned animal treated with NGF. $C$ and $D$, Medial septal nucleus of a control and an NGF-treated animal, respectively. Arrows indicate the median of the brain. Bars, $100 \mu \mathrm{m}$. ac, Nucleus accumbens; $h l$, horizontal limb of the diagonal band of Broca; $v l$, vertical limb of the diagonal band of Broca.

septal nucleus and the vertical limb of the diagonal band of Broca (Fig. 3), in confirmation of earlier findings (Daitz and Powell, 1954). This cell loss became evident 2-3 weeks after transections. During the first week after lesioning, enlarged cell bodies were occasionally observed in the septal area of the lesioned side.

AChE histochemistry after pretreatment with DFP, as performed in the present study, resulted in visualization of cell 
bodies in septum, nucleus of the the diagonal band of Broca, substantia innominata, and nucleus basalis in unlesioned control animals and on control sides of lesioned animals. AChE visualized after pretreatment with DFP has been shown to be a reliable marker for cholinergic neurons in these nuclei, since 80-90\% of all AChE-positive neurons were found to be costained for CAT (Eckenstein and Sofroniew, 1983; Levey et al., 1983). In lesioned control animals, the fimbrial transections resulted in a pronounced reduction of the number of $\mathrm{AChE}-$ positive cell bodies in the medial septal nucleus and in the vertical limb of the diagonal band on the brain side ipsilateral to the lesion (Fig. 4). The disappearance of AChE-positive cell bodies paralleled that of the large cell bodies visualized by Nissl staining. Reductions in the number of AChE-positive cells became maximal 2-3 weeks after lesioning. During the first week after transection, swollen AChE-positive fibers were found throughout the septal area (Fig. 3D).

The fact that fimbrial transections resulted at first in the appearance of swollen AChE-positive fibers, and later in the disappearance of $\mathrm{AChE}$-positive cell bodies and of the large cell bodies visualized by Nissl staining, indicates that these lesions produced retrograde degeneration of cholinergic cells located in the medial septal nucleus and the vertical limb of the diagonal band of Broca. Cholinergic neurons located in the horizontal limb of the diagonal band, in substantia innominata and nucleus basalis, were not affected by the lesions. These findings confirm that cholinergic neurons projecting to the hippocampus are located in medial septal nucleus and the vertical limb of the diagonal band (McKinney et al., 1983; Meibach and Siegel, 1977; Mesulam et al., 1983; Segal and Landis, 1974; Wainer et al., 1984).

\section{Effects of NGF treatment}

Since degenerative changes in the septal area after fimbrial transections were complete after 2-3 weeks, a period of 4 weeks was chosen to study the effects of NGF administration. In lesioned control animals receiving intraventricular injections of a control protein over 4 weeks, there was a pronounced loss of AChEpositive neurons, as observed before. In contrast, there was no obvious difference in the number of AChE-positive cells between the lesioned and the control side in all areas containing cholinergic cell bodies in lesioned animals chronically treated with NGF (Fig. 4).

For quantitative comparisons, cholinergic neurons projecting to the hippocampus (i.e., those located in the medial septal nucleus and the vertical limb of the diagonal band) were grouped together and compared with neurons not projecting to the hippocampus (i.e., those located in the horizontal limb of the diagonal band and the substantia innominata). The quantitative analysis was restricted to areas anterior to the anterior commissure and therefore did not include nucleus basalis (see Fig. 2). In lesioned control animals, the fimbrial transections reduced the number of AChE-positive cell bodies in medial septal nucleus and the vertical limb of the diagonal band to $50 \%$ of the number counted on the unlesioned side (Table 1). In contrast, in lesioned animals chronically treated with NGF, the number of AChE-positive cell bodies in these areas was reduced only by $12 \%$ on the lesioned side (Table 1 ). These findings indicate that the chronic intraventricular injections of NGF were able to attenuate the degeneration of cholinergic neurons produced by the fimbrial transections.

In contrast to the almost complete prevention by NGF of the lesion-induced disappearance of AChE-positive cell bodies, NGF treatment only partly counteracted the disappearance of large cell bodies observed in Nissl-stained sections. The number of large cell bodies on the lesioned sides of NGF-treated animals was higher than that on the lesioned sides of control animals, but did not reach control levels (Fig. 5). In sections of NGF-
Table 1. Effect of intraventricular injections of NGF on the number of cholinergic neurons surviving in basal forebrain nuclei after fimbrial transections ${ }^{a}$

\begin{tabular}{lcl} 
Animals & $\begin{array}{l}\text { Medial septum and } \\
\text { vertical limb of } \\
\text { diagonal band }\end{array}$ & $\begin{array}{l}\text { Horizontal limb } \\
\text { of diagonal } \\
\text { band and sub. } \\
\text { innominata }\end{array}$ \\
\hline $\begin{array}{l}\text { Controls }(9) \\
\text { Control side }\end{array}$ & $1428 \pm 114$ & $1407 \pm 120$ \\
Lesioned side & $696 \pm 69^{b}$ & $1260 \pm 111$ \\
$\quad(\%$ of control side) & $(49.9 \pm 3.9)$ & $(89.8 \pm 2.3)$ \\
NGF-treated (10) & & $1263 \pm 99$ \\
Control side & $1377 \pm 93$ & $1242 \pm 93$ \\
Lesioned side & $1209 \pm 99^{c}$ & $(98.8 \pm 2.1)$ \\
$\quad(\%$ of control side) & $(87.8 \pm 6.2)^{c}$ &
\end{tabular}

Animals were lesioned as described in the text and were injected intraventricularly over 4 weeks with NGF $(10 \mu \mathrm{g}$, twice weekly) or with equal amounts of a control protein (controls). Cholinergic neurons were visualized as described in the legend of Figure 2. To facilitate the counting of cholinergic cell bodies in the septal area, brains of lesioned animals were cut in a standardized manner. The sectioned part of the brain contained the entire medial septal nucleus and the diagonal band of Broca, i.e., the areas containing cell bodies projecting to the hippocampus. Twentyfour sections were taken between anteroposterior levels A9000 and A6700. Cholinergic cell bodies were ascribed to one of the following groups: to medial septal nucleus and the vertical limb of the diagonal band of Broca (i.e., areas containing cholinergic neurons projecting to the hippocampus); or to the horizontal limb of the diagonal band and substantia innominata (i.e., areas containing cholinergic neurons not projecting to the hippocampus). The total number of cholinergic cell bodies was calculated by multiplying the number of counted cells in 24 sections by 3 , thereby accounting for the fact that every third section only was taken for analysis.

a Means \pm SEM; number in parentheses indicates number of animals analyzed.

${ }^{b}$ Different from corresponding side; $p<0.01$ (analysis of variance).

- Different from lesioned side of control animals; $p<0.01$ (analysis of variance).

treated animals taken for both $\mathrm{AChE}$ and Nissl staining, all the large cell bodies on the lesioned sides were co-stained for AChE (Fig. 6). On control sides, approximately half of the large cell bodies showed positive staining for $\mathrm{AChE}$, confirming earlier findings indicating that cholinergic neurons represent $30-50 \%$ of the entire population of large cell bodies in the medial septal nucleus and the diagonal band of Broca (Mesulam et al., 1983; Wainer et al., 1985). These non-cholinergic neurons also contribute to the septo-hippocampal pathway (Wainer et al., 1985). The findings of the present study suggest that NGF treatment only counteracts the lesion-induced degeneration of the cholinergic septo-hippocampal neurons, but not that of other types of septal neurons contributing to this pathway.

\section{Discussion}

The results of the present study indicate that NGF promotes the survival of forebrain cholinergic neurons after axonal transection. Earlier findings had demonstrated that NGF was able to elevate CAT levels in forebrain cholinergic neurons studied in vivo and in vitro (Gnahn et al., 1983; Hefti et al., 1984, 1985; Honegger and Lenoir, 1982; Toniolo et al., 1985). However, in cultures of fetal septal neurons, NGF failed to promote the survival of cholincrgic ncurons (Hefti et al., 1985). On the basis of these findings, it had been concluded that the role of NGF in the function of forebrain cholinergic neurons was limited to a regulation of the synthesis of transmitter-specific enzymes (Hefti et al., 1985). The findings of the present study significantly broaden the role of NGF in the function of forebrain cholinergic neurons by indicating that NGF is able to affect the survival of these cells.

Transection of peripheral nerves does not result in degeneration of neurons but, rather, leads to the characteristic chro- 

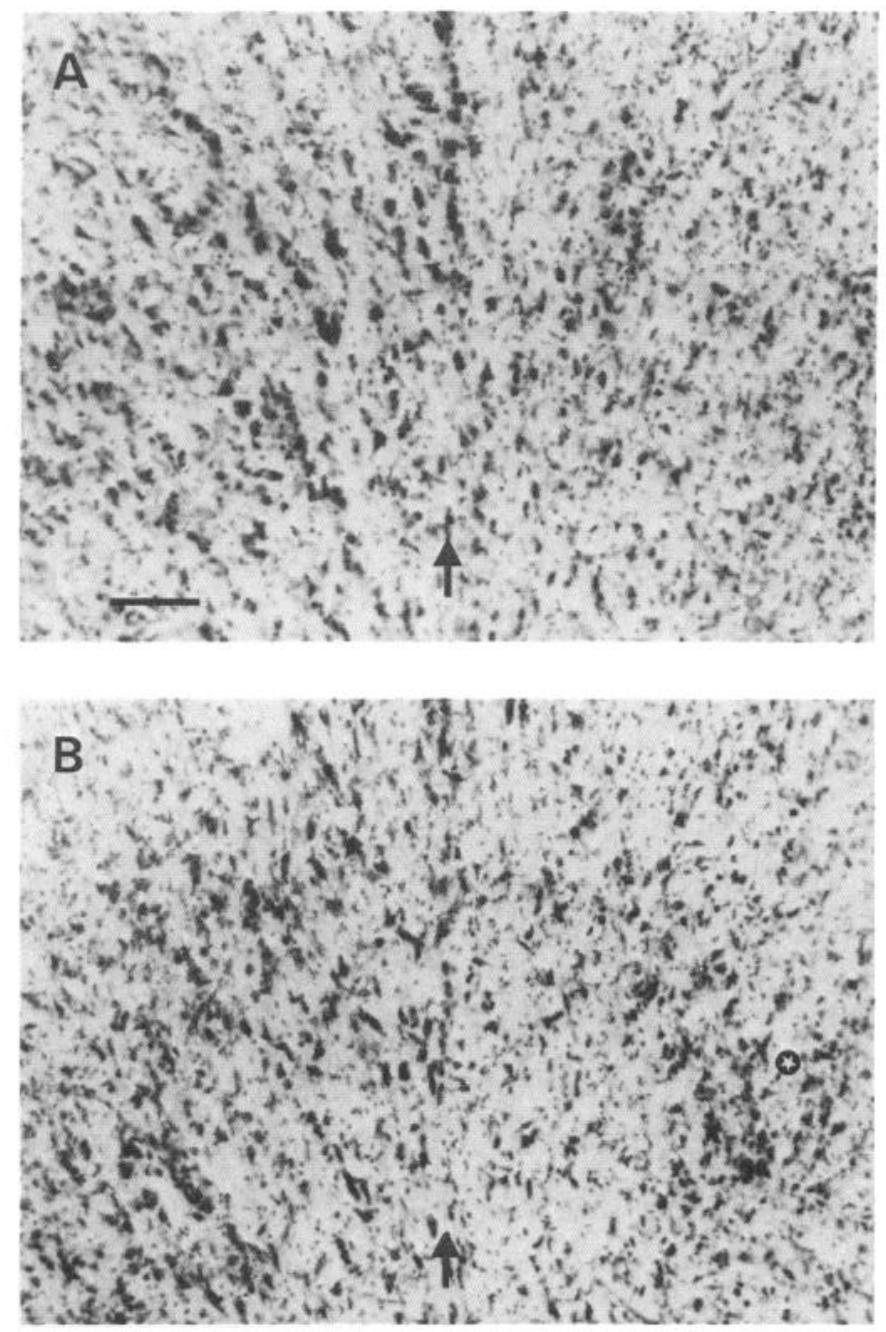

Figure 5. Effect of chronic intraventricular administration of NGF on the number of Nissl-stained cell bodies in the medial septal nucleus after fimbrial transection. Animals were treated as described in the legend of Figure 4, and were then taken for staining with cresyl violet. $A$ and $B$, Medial septal nucleus of a control animal and of a NGFtreated animal, respectively. Arrows indicate the median of the brain. Asterisk points to an area containing large cell bodies on the lesioned side of an NGF-treated animal. Bar, $100 \mu \mathrm{m}$.

matolytic response of the cell body and axonal regeneration. In cholinergic motoneurons and autonomic ganglion cells, chromatolysis is associated with reduced expression of AChE (for a review, see Lieberman, 1971). On the basis of these facts, it could be argued that the disappearance of AChE staining in the septal area after fimbrial transections, as was observed in the present study, does not reflect degeneration of cholinergic neurons but only a down-regulation of AChE synthesis. However, results obtained with Nissl staining clearly indicate a loss of large cell bodies in medial septal nucleus and in the diagonal band of Broca ( $c f$. Figs. 3, 5, and 6). These findings are in agreement with those of an earlier study reporting extensive cell loss after fimbrial transections in rats (Daitz and Powell, 1954). NGF treatment resulted in a partial prevention of the loss of Nissl-stained large cell bodies in the septal area, in accordance with the fact that $30-50 \%$ of the large cells in medial septal nucleus and the diagonal band are cholinergic. This very strongly suggests that septal cholinergic neurons indeed degenerate after fimbrial transections and that NGF is able to promote their survival. However, the findings do not completely rule out the possibility that fimbrial transections did not result in degener- ation of cell bodies, but only in shrinkage associated with a complete loss of $\mathrm{AChE}$ expression. Shrinkage of cholinergic neurons located in nucleus basalis has been reported to occur after cortical damage in the rat (Sofroniew et al., 1983) and in the brains of patients affected with Alzheimer's disease (Pearson et al., 1983). However, even though smaller in size, these cholinergic neurons still expressed the cholinergic enzymes CAT and $\mathrm{AChE}$, and their cell bodies could be visualized using histological techniques for both these markers. Therefore, there is no example of axonal transection resulting in shrinkage of the cell body and complete loss of transmitter-specific enzymes, and it seems most probable that, in the present study, fimbrial transection did indeed result in degeneration of the forebrain cholinergic neurons.

The septo-hippocampal pathway lesioned in the present study represents the best-characterized part of the ascending cholinergic projection of the basal forebrain, which innervates cortex and hippocampus (McKinney et al., 1983; Mesulam et al., 1983; Wainer et al., 1984). The septo-hippocampal pathway was chosen to study the effects of NGF on the survival of cholinergic neurons after injury because its anatomy is well described and the fibers coursing through the fimbria are easily accessible for lesioning (Meibach and Siegel, 1977; Milner et al., 1983; Nadler et al., 1974; Segal and Landis, 1974). All parts of the ascending cholinergic neurons apparently react to NGF since, besides promoting survival of septal cholinergic neurons, NGF also stimulates survival of cholinergic neurons from nucleus basalis in vitro (F. Hefti, unpublished observations). Furthermore, NGF injected into hippocampus and cortex is taken up and transported in retrograde fashion to cell bodies in septum and nucleus basalis (Seiler and Schwab, 1984). Furthermore, cholinergic interneurons of the striatum have been reported to react to NGF (Mobley et al., 1985; Martinez et al., 1985). Ascending cholinergic neurons of the basal forebrain and cholinergic striatal interneurons seem to be the only groups of central neurons that react to NGF. NGF's lack of effect on central catecholaminergic neurons has been amply demonstrated (Dreyfus et al., 1980; Konkol et al., 1978; Schwab et al., 1979). In cultures of brain neurons in which NGF elevated CAT activity, the activities of enzymes involved in the synthesis of GABA and catecholamines were not affected (F. Hefti, unpublished observations). Furthermore, NGF injected into hippocampus and cortex is taken up and transported in retrograde fashion by forebrain cholinergic neurons only, and not by other neurons having terminals in these areas (Schwab et al., 1979; Seiler and Schwab, 1984). However, the effects of NGF are not related to the type of transmitter used by a neuron. In the PNS, catecholaminergic sympathetic neurons are affected. In the brain, both cholinergic neurons of the basal forebrain and of the corpus striatum, but not the cholinergic motoneurons, respond to NGF (Dribin and Barrett, 1980; Mobley et al., 1985; Smith and Appel, 1983).

Fimbrial transections, as described in the present study and performed bilaterally, result in deficits in the rats' performance in a radial maze task. These behavioral deficits are alleviated by chronic intraventricular applications of NGF (Will and Hefti, 1985). Given the finding that NGF increases CAT activity in remaining cholinergic fibers in such animals (Hefti et al., 1984), it has been hypothesized that these behavioral improvements might be due to a facilitation of cholinergic transmission in the hippocampus. The findings of the present study indicate that such an effect might also be mediated by septal cholinergic neurons rescued by NGF from lesion-induced degeneration. The notion that NGF's effect on radial maze performance involves cholinergic neurons is supported by the fact that these neurons have a major role in memory function (Bartus et al., 1982; Biedermann, 1975; Davies, 1985; Matthies, 1974). However, at the present time there is no evidence that directly supports the notion that the NGF-mediated improvement in behavioral performance involves changes in cholinergic transmission, and 


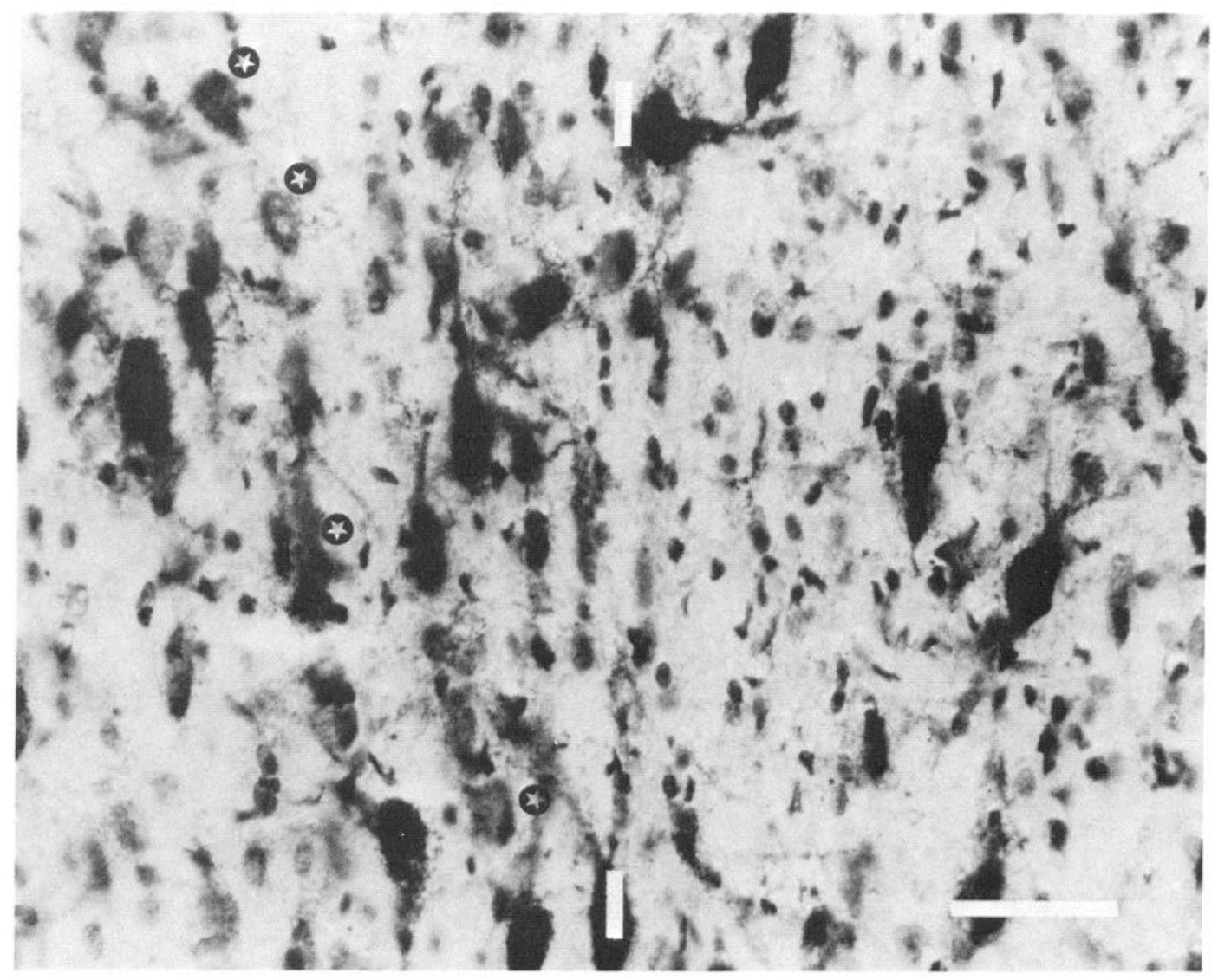

Figure 6. Combined Nissl- and AChE-staining of medial septal nucleus of an animal with a unilateral fimbrial transection, and treated with NGF. Vertical bars indicate position of the brain median. Large, strongly stained cell bodies represent AChE-positive cells, which are found on both sides of the brain. Weak staining indicates Nissl stain. Large, AChE-negative cell bodies visualized with Nissl staining (indicated by asterisks) are present on the control, but not on the lesioned (right), side. Horizontal bar, $50 \mu \mathrm{m}$.

the possibility that the effect is mediated by other neuronal systems cannot be excluded.

The findings of this study have implications for human Alzheimer's disease, which is associated with a selective loss of cholinergic neurons of the basal forebrain (Bartus et al., 1982; Coyle et al., 1983; Davies, 1985). Even though some other neuronal systems are also affected, the loss of cholinergic neurons seems to be a principal factor responsible for the memory loss that is characteristic of this disease. A treatment preventing the degeneration of these neurons would therefore be of great value in the therapy of this disease. Such a therapeutic tool might promote the survival of remaining cholinergic neurons in mildly affected patients and might therefore prevent the normally progressive behavioral deterioration. I have earlier hypothesized that the selective loss of cholinergic neurons in Alzheimer's disease might be caused by a lack of NGF available to these neurons (Hefti, 1983). The idea was based on the general hypothesis of Appel (1981), who suggested that diseases associated with selective neuronal degeneration might be due to absence of the corresponding neurotrophic factor. I also drew attention to the possibility that NGF, or drugs mimicking NGF's actions, might be useful in the treatment of Alzheimer's disease. The new findings indicating that, in experimental animal models, NGF promotes the survival of cholinergic neurons after axonal injury strongly support this notion.

\section{References}

Appel, S. H. (1981) A unifying hypothesis for the cause of amyotrophic lateral sclerosis, parkinsonism, and Alzheimer's disease. Ann. Neurol. 10: 499-505.

Bartus, R. T., R. L. Dean, B. Beer, and A. S. Lippa (1982) The cho- linergic hypothesis of geriatric memory dysfunction. Science 217 : 408-417.

Biedermann, G. B. (1975) The search for the chemistry of memory; recent trends and the logic of investigation in the role of cholinergic and adrenergic transmitters. In Progress in Neurobiology, Vol. 2, G. A. Kerkut and J. W. Phyllis, eds., Pergamon, New York.

Bocchini, V., and P. Angeletti (1969) The nerve growth factor: Purification as a 30,000-molecular weight protein. Proc. Natl. Acad. Sci. USA 64: 787-794.

Butcher, L. L., K. Talbot, and L. Bilezikjian (1975) Acetylcholinesterase neurons in dopamine-containing regions of the brain. J. Neural Transm. 37: 127-138.

Clark, G. (1981) Staining Procedures, Williams \& Wilkins, Baltimore, MD.

Coyle, J. T., D. L. Price, and M. R. DeLong (1983) Alzheimer's disease: A disease of cortical cholinergic innervation. Science 219:1184-1189.

Crutcher, K. A., and F. Collins (1982) In vitro evidence for two distinct hippocampal growth factors: Basis of neuronal plasticity? Science 217: 67-70.

Crutcher, K. A., and J. N. Davis (1981) Sympathetic noradrenergic sprouting in response to central cholinergic denervations. Trends Neurosci. 4: 70-72.

Crutcher, K. A., L. Brothers, and J. N. Davis (1979) Sprouting of sympathetic nerves in the absence of afferent input. Exp. Neurol. 66: 778-783.

Daitz, H. M., and T. P. S. Powell (1954) Studies of the connections of the fornix system. J. Neurol. Neurosurg. Psychiatry 17: 75-82.

Davies, P. (1985) Is it possible to design rational treatment for the symptoms of Alzheimer's disease? Drug Dev. Res. 5: 69-75.

Dreyfus, C. F., E. R. Peterson, and S. M. Crain (1980) Failure of nerve growth factor to affect fetal mouse brain catecholaminergic neurons in culture. Brain Res. 194: 540-551.

Dribin, L. B., and J. N. Barrett (1980) Conditioned medium enhances 
neuritic outgrowth from rat spinal cord explants. Dev. Biol. 74: 184195.

Eckenstein, F., and M. W. Sofroniew (1983) Identification of central cholinergic neurons containing both choline acetyltransferase and acetyl-cholinesterase and of central neurons containing only acetyl-cholinesterase. J. Neurosci. 3: 2286-2291.

Geneser-Jenden, F. A., and T. E. Blackstad (1979) Distribution of acetylcholinesterase in the hippocampal region of the guinea pig. I. Entorhinal area, parasubiculum, and pre-subiculum. Z. Zellforsch. 114: 460-481.

Gnahn, H., F. Hefti, R. Heumann, M. Schwab, and H. Thoenen (1983) NGF-mediated increase of choline acetyltransferase (ChAT) in the nconatal forebrain; evidence for a physiological rolc of NGF in the brain? Dev. Brain Res. 9: 45-52.

Greene, L. A., and E. M. Shooter (1980) The nerve growth factor: Biochemistry, synthesis, and mechanism of action. Annu. Rev. Neurosci. 3: 353-402.

Hefti, F. (1983) Alzheimer's disease caused by a lack of nerve growth factor? Ann. Neurol. 13: 109-110.

Hefti, F., A. Dravid, and J. Hartikka (1984) Chronic intraventricular injections of nerve growth factor elevate hippocampal choline acetyltransferase activity in adult rats with partial septo-hippocampal lesions. Brain Res. 293: 305-309.

Hefti, F., J. Hartikka, F. Eckenstein, H. Gnahn, R. Heumann, and M. Schwab (1985) Nerve growth factor (NGF) increases choline acetyltransferase but not survival or fiber growth of cultured septal cholinergic ncurons. Ncuroscience 14: 55-68.

Honegger, P., and D. Lenoir (1982) Nerve growth factor (NGF) stimulation of cholinergic telencephalic neurons in aggregating cell cultures. Dev. Brain Res. 3: 229-238.

Koenig, J. F. R., and R. A. Klippel (1963) The rat brain. A stereotaxic atlas of the forebrain and lower parts of the brain stem. Williams \& Wilkins, Baltimore, MD.

Konkol, R. J., R. B. Mailman, E. G. Bendeich, A. M. Garrison, R. A. Mueller, and G. R. Breese (1978) Evaluation of the effects of nerve growth factor and anti-nerve growth factor on the development of central catecholaminergic neurons. Brain Res. 144: 277-285.

Korsching, S., G. Auburger, R. Heumann, J. Scott, and H. Thoenen (1985) Levels of nerve growth factor and its mRNA in the central nervous system of the rat correlate with cholinergic innervation. EMBO J. 4: 1389-1393.

Levey, A. I., B. H. Wainer, E. J. Mufson, and M. M. Mesulam (1983) Colocalization of acetylcholinesterase and choline acetyltransferase in the rat cerebrum. Neuroscience $9: 9-22$.

Lieberman, A. R. (1971) The axon reaction: A review of the principal features of perikaryal responses to axon injury. Int. Rev. Neurobiol. 14: 49-123.

Loy, R., and R. Y. Moore (1977) Anomalous innervation of the hippocampal formation by peripheral sympathetic axons following mechanical injury. Exp. Neurol. 57: 645-650.

Martinez, H. J., C. F. Dreyfus, D. G. Jonakait, and I. B. Black (1985) Nerve growth factor promotes cholinergic development in brain striatal cultures. Proc. Natl. Acad. Sci. USA 82: 7777-7781.

Matthies, H. (1974) The biochemical basis of learning and memory. Life Sci. 15: 2017-2031.

McKinney, M., J. T. Coyle, and J. C. Hedreen (1983) Topographic analysis of the innervation of the rat neocortex and hippocampus by the basal forebrain cholinergic system. J. Comp. Neurol. 217:103121.

Meibach, R. C., and A. Siegel (1977) Efferent connections of the septal area in the rat: An analysis utilizing retrograde and anterograde transport methods. Brain Res. 119: 1-20.

Mesulam, M. M., E. J. Mufson, B. H. Wainer, and A. I. Levey (1983) Central cholinergic pathways in the rat: An overview based on an alternative nomenclature (Ch1-Ch6). Neuroscience 10:1185-1201.

Milner, T. A., R. Loy, and D. G. Amaral (1983) An anatomical study of the development of the septo-hippocampal projection in the rat. Dev. Brain Res. 8: 343-371.

Mobley, W. C., J. L. Rutkowski, G. I. Tennekoon, K. Buchanan, and M. V. Johnston (1985) Choline acetyltransferase activity in striatum of neonatal rats increased by nerve growth factor. Science $229: 284$ 286.

Nadler, J. V., D. A. Mattews, C. W. Cotman, and G. S. Lynch (1974) Development of cholinergic innervation in the hippocampal formation of the rat. Dev. Biol. 36: 142-154.

Pearson, R. C. A., M. V. Sofroniew, A. C. Cuello, T. P. S. Powell, F. Eckenstein, M. M. Esiri, and G. K. Wilcock (1983) Persistence of cholinergic neurons in the basal nucleus in a brain with senile dementia of the Alzhcimer's type demonstrated by immunohistochemical staining for choline acetyltransferase. Brain Res. 289: 375-379.

Riopelle, R. J., P. M. Richardson, and V. M. K. Verge (1985) Receptors for nerve growth factor in the rat central nervous system. Proc. Soc. Neurosci. 11: 1056 .

Schwab, M., U. Otten, Y. Agid, and H. Thoenen (1979) Nerve growth factor (NGF) in the rat CNS: Absence of specific retrograde axonal transport and tyrosine hydroxylase induction in locus coeruleus and substantia nigra. Brain Res. 168: 473-483.

Segal, M., and S. Landis (1974) Afferents to the hippocampus of the rat studied with the method of retrograde transport of horseradish peroxidase. Brain Res. 78: 1-15.

Seiler, M., and M. E. Schwab (1984) Specific retrograde transport of nerve growth factor (NGF) from neocortex to nucleus basalis in the rat. Brain Res. 300: 33-36.

Shelton, D. L., and L. F. Reichardt (1986) Studies on the expression of the nerve growth factor (NFG) gene in the central nervous system: Level and regional distribution of NGF mRNA suggests that NFG functions as a trophic factor for several distinct populations of neurons. Proc. Natl. Acad. Sci. USA 83: 2714-2718.

Smith, R. G., and S. H. Appel (1983) Extracts of skeletal muscle increase neurite outgrowth and cholinergic activity of fetal rat spinal motor neurons. Science 219: 1079-1081.

Sofroniew, M. V., R. C. A. Pearson, F. Eckenstein, A. C. Cuello, and T. P. S. Powell (1983) Retrograde changes in cholinergic neurons in the basal forebrain of the rat following cortical damage. Brain Res. 289: 370-374

Stenevi, U., and A. Bjorklund (1978) Growth of vascular sympathetic axons into the hippocampus after lesions of the septo-hippocampal pathway; a pitfall in brain lesion studies. Neurosci. Lett. 7:219-224.

Suda, K., Y. A. Barde, and H. Thoenen (1978) Nerve growth factor in mouse and rat serum: Correlation between bioassay and radioimmunoassay determinations. Proc. Natl. Acad. Sci. USA 75: 4042 4046.

Thoenen, H., and Y. A. Barde (1980) Physiology of nerve growth factor. Physiol. Rev. 60: 1284-1335.

Toniolo, G., S. B. Dunnett, F. Hefti, and B. Will (1985) Acetylcholinerich transplants in the hippocampus: influence of intrinsic growth factors and application of NGF on choline acetyltransferase activity. Brain Res. 345: 141-146.

Varon, S., and R. Adler (1980) Nerve growth factors and control of nerve growth. Curr. Top. Dev. Biol. 16: 207-252.

Vinores, S., and G. Guroff (1980) Nerve growth factor: Mechanism of action. Annu. Rev. Biophys. Bioeng. 9: 223-257.

Wainer, B. H., A. I. Levey, E. F. Mufson, and M. M. Mesulam (1984) Cholinergic systems in mammalian brain identified with antibodies against choline acetyltransferase. Neurosci. Int. 6: 163-182.

Wainer, B. H., A. I. Levey, D. B. Rye, M. M. Mesulam, and E. J. Mufson (1985) Cholinergic and non-cholinergic septohippocampal pathways. Neurosci. Lett. 54: 45-52.

Will, B., and F. Hefti (1985) Behavioral and neurochemical effects of chronic intraventricular injections of nerve growth factor in adult rats with fimbria lesions. Behav. Brain Res. 17: 17-24. 